\title{
A Novel Method for Technology Forecasting and Developing R\&D Strategy of Building Integrated Photovoltaic Technology Industry
}

\author{
Yu-Jing Chiu ${ }^{1}$ and Tao-Ming Ying ${ }^{2}$ \\ ${ }^{1}$ Department of Business Administration, Chung Yuan Christian University, 200 Chung Pei Road, \\ Chung Li 32023, Taiwan \\ ${ }^{2}$ Department of Construction Engineering, National Taiwan University of Science and Technology, \\ No. 43, Section 4, Keelung Road, Da'an District, Taipei City 106, Taiwan
}

Correspondence should be addressed to Yu-Jing Chiu, yujing@cycu.edu.tw

Received 24 February 2012; Revised 17 May 2012; Accepted 22 May 2012

Academic Editor: Jung-Fa Tsai

Copyright (c) 2012 Y.-J. Chiu and T.-M. Ying. This is an open access article distributed under the Creative Commons Attribution License, which permits unrestricted use, distribution, and reproduction in any medium, provided the original work is properly cited.

Because of global warming, renewable energy technologies have become more essential currently, with solar energy technology advancing worldwide. Therefore, interdisciplinary integration is an important trend, and building-integrated photovoltaic (BIPV) is an emerging technology involving the photovoltaic and building fields. The purpose of this study is to understand the technology evolution of BIPV and to determine the R\&D planning direction. This paper proposes a hybrid approach to explore the life cycle of BIPV technology and develop the R\&D strategy of related industries. The proposed approach comprises the following submodules. First, patent analysis is employed to transform patent documents into structured data. Second, the logistic growth model is used to explore the life cycle of BIPV technology. Third, a patent matrix map analysis is used to develop the R\&D strategy of the BIPV industry. Through the analysis by the logistic model, the BIPV technology is transformed from the emerging stage to the growth stage of a long-term life cycle. The other important result is created by the three-dimensional matrix for R\&D strategies in this paper.

\section{Introduction}

Issues of energy conservation and prevention of global warming have been of great concern in recent years. For energy shortages, the development of renewable energy technologies is an inevitable trend and includes solar, wind, hydro- and bio-mass energy. There are advantages to solar energy, including that it is natural, nonpolluting, inexhaustible, noiseless, and not subject to geographical constraints. Solar energy contains few moving parts, and therefore, needs almost no maintenance. The cost of solar energy is fixed at the initial investment stage. 
It is the parity technology in the long-term operation. Solar energy technology can be divided into the ground-based system, rooftop system, and building-integrated photovoltaic (BIPV) system. Since the ground-based system needs considerable land and the rooftop system is restricted to a limited number of building roofs, this study focuses on the BIPV system, which is used to construct three-dimensional space to create the largest possible photovoltaic power generation with less area. In addition, solar energy technology can be embedded in various ways of designed buildings, which not only has the ability to improve the use of renewable energy but is also by far the oldest and the most cleanly green energy worldwide. BIPV will gain increasing attention of the building energy efficiency market in the twenty-first century.

Consequently, the ability to manage intellectual property plays a critical role in the $\mathrm{R} \& \mathrm{D}$ process or new product development. The report of the World Intellectual Property Organization (WIPO) shows that $90 \%-95 \%$ of the world's inventions can be found in patent documents, and $80 \%$ of these technologies do not appear in other resources, such as journals, magazines, and encyclopedias [1]. Moreover, a WIPO investigation showed that a company can save up to $60 \%$ of time in R\&D and $40 \%$ of research budget if it can use patent documents efficiently. Patents contain substantial information including practical and specific technological content, technical reporting, technological trends of firms, and technological development trends [2]. Patent information is a sufficient source of technical knowledge, and the patent contains characteristics of the technology and market because it fulfills a clear standard and originality, technical feasibility, and commercial value [3]. It can also be the basis of technical competitive analysis and technology trends analysis [4], and it can be regarded as an important indicator of technological changes [5]. Therefore, to master the technology development trend and competitive advantage of enterprises, we must rely on detailed patent intelligence to fully achieve maximum value from patent analysis [6].

The analysis of patent databases can provide the latest information technology and product. The growth of the number of patents may represent a national or industrial development of technology. It is a leading indicator of competitiveness, allowing one to grasp the message of patent data and analysis of industry trends to trace an evasive technology or technological innovation development strategy. follows:

Many experts and scholars used patent analysis to investigate different levels as

(1) discussion of national economic growth or innovation activities: Barroso et al. [7] studied 21 Latin American countries, including analysis of patents as a source of technical information to improve scientific and technological research and development and innovation in their own countries; Abraham and Moitra [8] used patent analysis to accurately assess the technical progress and technical innovation;

(2) discussion of enterprise technology ability: Liu and Shyu [1] used patent analysis of Taiwan LED and TFT industry technology development, strategy, and technology planning and forecasting. Ernst [9] analyzed the German mechanical engineering industry and four patent strategies of performance associated with the company;

(3) discussion of distribution of industries or enterprises: Guo [10] analyzed Taiwan national patent database (TWPAT) for the number of applications and development trend. Chen and Cheng [11] analyzed the US patent database (USPTO) in patent classification and UPC solar patent analysis research;

(4) an analysis of patent citation data: Hu [12] studied the USPTO citation data seeking knowledge of the East Asian regional traffic. Tijssen [13] related to patent 
citation analysis of global and domestic industry of interaction between science and technology and knowledge flows.

Technology forecasting is the theory and practice of technology development strategy. Many researchers have combined patent analysis with different technology prediction methods to identify future development trends and strategies. Trappey et al. [14] constructed the multitechnology cluster to analyze the RFID (radio frequency identification) technology forecasting model. They discussed future development strategies of industry by analyzing RFID patent clustering, which has reached the saturation stage of the technology life cycle. This model provided systematic quantitative analysis of technology development and supported expert intuition and judgment [15]. Chen et al. [16] considered the time dimension of technology forecasting. He stated that the $S$-curve was an effective quantitative technology forecasting model for cumulatively analyzing patents. However, researcher ability limited patent data analysis, and the accuracy and reliability of the data also affected analysis accuracy. Therefore, Cheng et al. [17] used the FAHP (fuzzy analytic hierarchy process) method as a technology forecasting method to evaluate and select novel material fields in a rapidly changing environment.

However, it is more important for an $R \& D$ manager to know how to master the market of technology imports and the exit market of time. If an enterprise wants to keep a competitive advantage, it must establish a technology forecasting system [18]. According to technology life cycle displayed by $S$-curve, we can effectively understand the technology development track.

Technology forecast is through text or digital form to describe future machinery, entity program, and the application of program and development [19]. Technology forecasters must focus on changes of technology function, the significance of innovation, and the implementation of time points. Technology forecasting of content contains technology ability of growth, replacement rate of old and new technology, situation of technology diffusion, market penetration, and future possibilities [20]. There are three types of technological prediction methods. They are direct forecasting, correlative forecasting, and structural forecasting. However, as the technology industry competition intensifies and technology development continues in the globalized world, technology forecasting must master the principles of accurate, fast, and simple to achieve the desired results. Therefore, we use the direct forecasting method by reliable patent data in this study.

We are interested in the BIPV's development and aim to explore its evolution. This study examines the viewpoint of patent analysis and hopes to offer some useful recommendations for BIPV's technology development. Thereby, we use a logistic model to explore the life cycle of BIPV technology development. The patent database of the United States Patent and Trademark Office (USPTO) is by patent number. We combine logistic growth model analysis of embryonic development of BIPV technology trends and forecasts to allow industry R\&D managers to develop technology strategies for future planning.

\section{BIPV Technology and Industry}

All energy consumption in a building includes raw-material production, construction process, decoration, and the final usage stage. Through the combination of solar power technology and building itself, the building can function as a power generator. Here, photovoltaic modules are fabricated as building material and facilitate the building to convert 


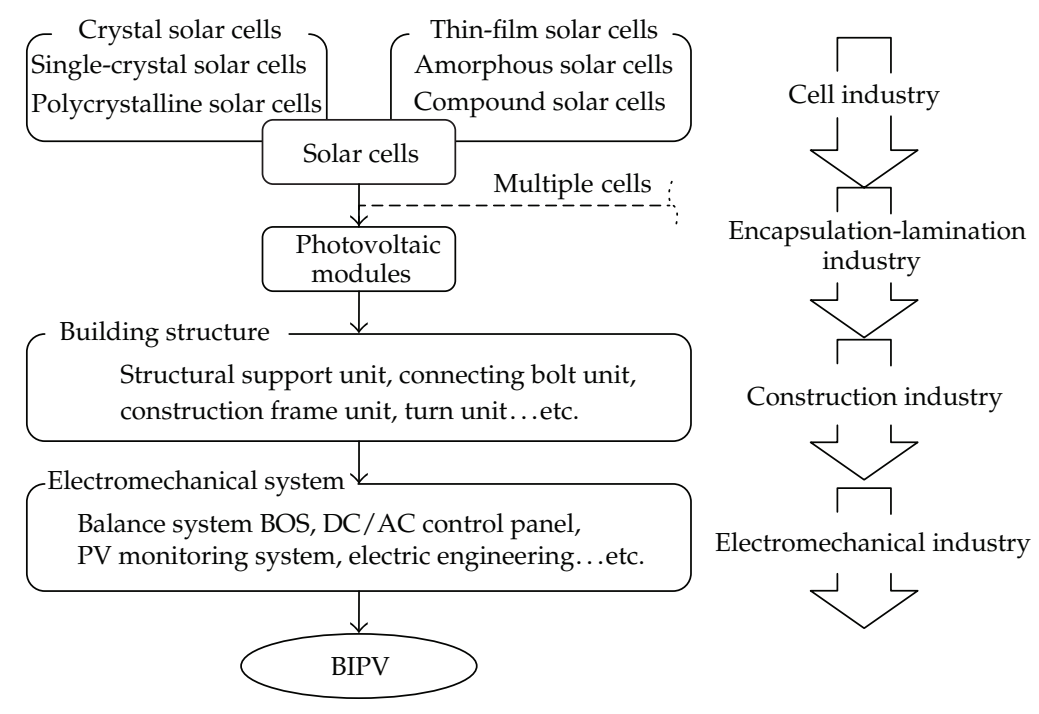

Figure 1: BIPV technology industry chain.

solar energy into electricity. Therefore, BIPV can be called a static generator as well as the new generation of photovoltaic building [21].

BIPV is a new concept of converting solar energy into electrical energy. In addition to developing self-efficient zero-energy buildings (ZEB) with the use of BIPV, heat load within the building can be reduced via the thermal resistance of the photovoltaic module and then achieve the dual effect of energy saving and carbon reduction. At the same time, the excess of clean energy can be sold back to the commercial electricity providers to sell to other customers, thus creating a multiple effect of energy saving and carbon reduction. In the future, the integrated distribution of BIPV electricity network will form the solar power grid of a metropolitan area that we might call a photovoltaic city.

The methods of integrating photovoltaic and building can be distinguished into two kinds of technology: installed PV module above a building and PV module integrated with the building. BIPV's technology industry chain can be divided into four flows, including solar cells, photovoltaic modules, building structure, and electromechanical system (Figure 1). The industry chain goes from the most upstream raw material of the silicon, a seed crystal puller rod for growing silicon boule, and then cuts into a silicon wafer, which is the main source of solar cells. After being made into solar cells that can be converted into energy, the solar cells are linked together in modules. Later, these solar modules are combined with a balance system (balance system BOS) into a form such as the converter, current breaker, building support structures, power cables, and monitoring instrumentation and then finally installed.

Figure 1 shows technology and market chain relationships for the BIPV industry. It is possible to clearly understand technology and market relationships in the BIPV industry. For example, PV manufacturers must consider and consistently comply with national building codes when developing products; the construction and electromechanical industries in the wiring and installation of PV modules; electrical and mechanical piping interface design, integration, and coordination when building a high-performance, high-security system; visual appeal. Finally, BIPV building systems are handed to market users after completion and achieve effective energy savings and carbon reduction, furthering the realization of zeroenergy buildings. 


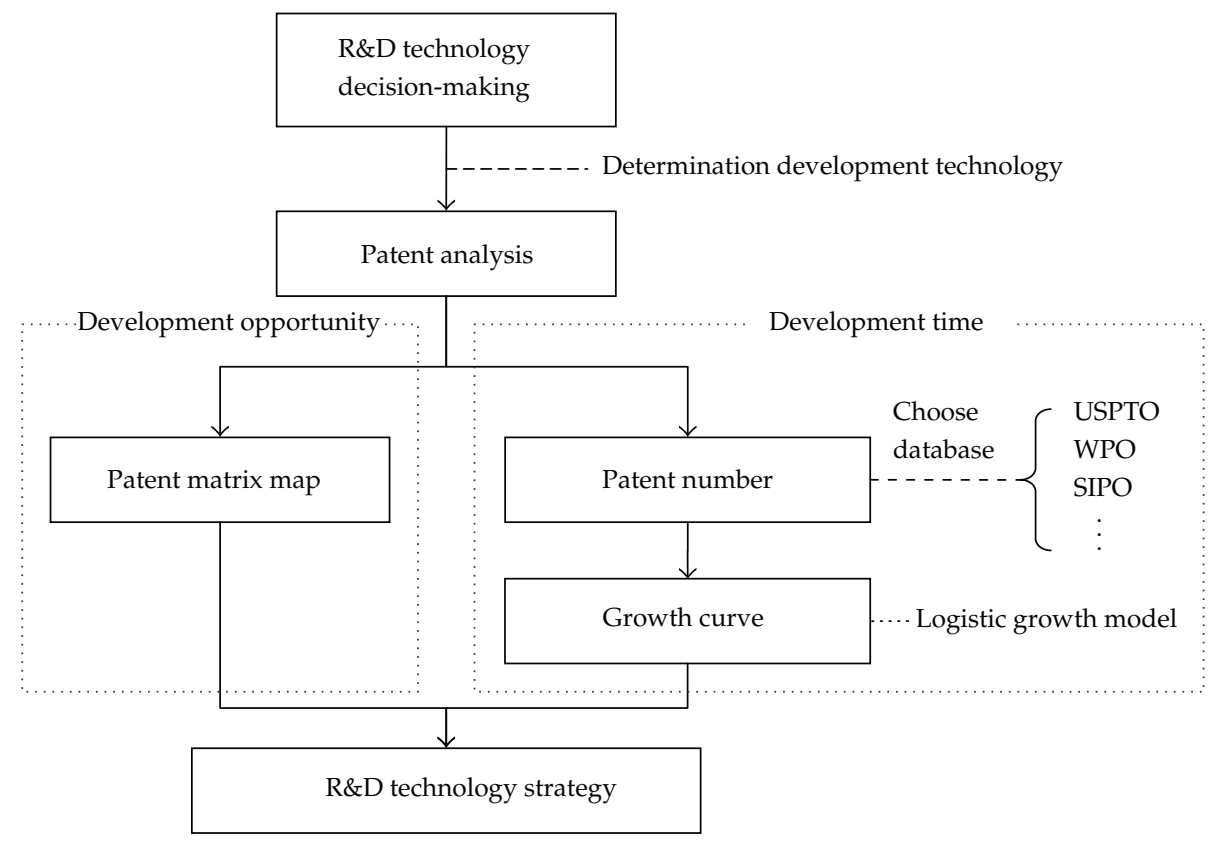

Figure 2: R\&D technology strategy model.

Since BIPV is integrated into the three-dimensional space with the building structure and does not take up any additional ground space, BIPV is the best model of applying renewable energy in the highly urbanized area. However, its installation cost is high, which affects the development of market demand. Therefore, when developed countries are promoting renewable energy, they rely on the government's four policy factors, including incentive policy, subsidies, low installation cost, quick approval process, and lending policies for financial institutions, which sustain the promotion of the BIPV industry and market development. In the future, the key factor in reducing the impact on market development is the continuity of technology development. The installation cost, meaning the economies of scale of the BIPV industry, could flourish unimaginably when the cost of solar photovoltaic electricity and cost of commercial electricity are balanced.

\section{Methodology}

For this study, we intend to explore completed lifecycle evolution of BIPV technology. The quantity and quality of data acquisition are priorities and explicitly defining the industry technology is necessary to avoid forecasting bias. For the above reasons, we adapt the expert opinions and growth curve to develop the forecasting models. Therefore, we combined patent analysis, growth curve, and expert opinions to analyze the development of BIPV technology and construct the R\&D strategy. The framework of this study is presented in Figure 2. These are summarized below.

\subsection{Patent Searching}

Patent searching is based on a specific field of study, through the relevant patent documents issued by relevance of patent data search, application for the analysis, and followup of 


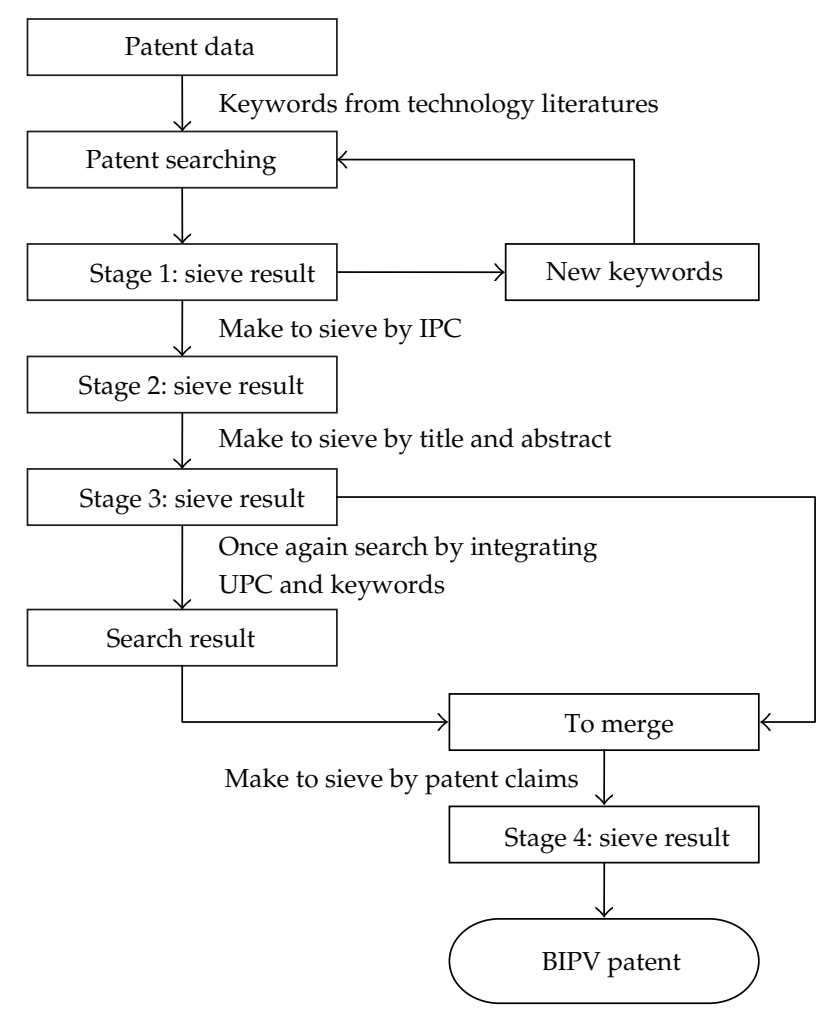

Figure 3: Process of BIPV patent searching.

research. We must understand its retrieval application purpose, scope, search method, and search tools before patent searching. This research through the patent analysis is to predict technology trends and use the BIPV technologies as scope, and then to group Boolean searches through the USPTO patent database of keywords (Boolean Search), its use of the retrieval tools patented analysis software developed for Lian Ying Technology Patent and Patent Guider 2008 Tech tools for analysis. The patent searching strategies for this study are the main access point to keywords and to supplement, patent classification (international patent classification (IPC)), to achieve the accuracy and integrity of the retrieval processes in Figure 3.

\subsection{Keywords Extraction}

To construct our patent map, keywords are required first. It forms important patent search methods by technical or patent documents for keywords, and keywords in groups to a logical combination of relevance. Therefore, the processes of keywords extraction are including literature review, compile keywords, re-searching and find out new keywords, and establish the keywords pool (Figure 4). After literature review, the three parts keywords of BIPV industry chain can be extracted. The new keywords found in the retrieval process to establish more complete keywords pool of BIPV (Figure 5). 


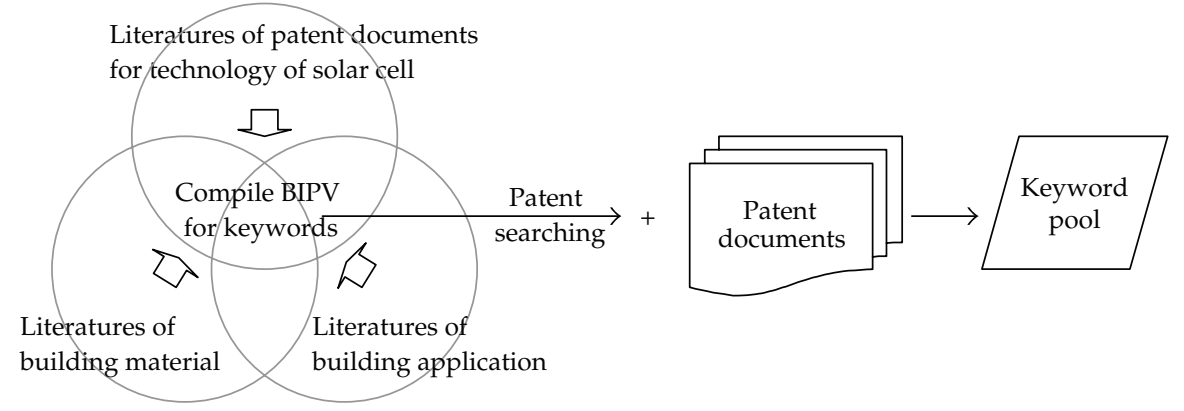

Figure 4: The process of keywords extraction.

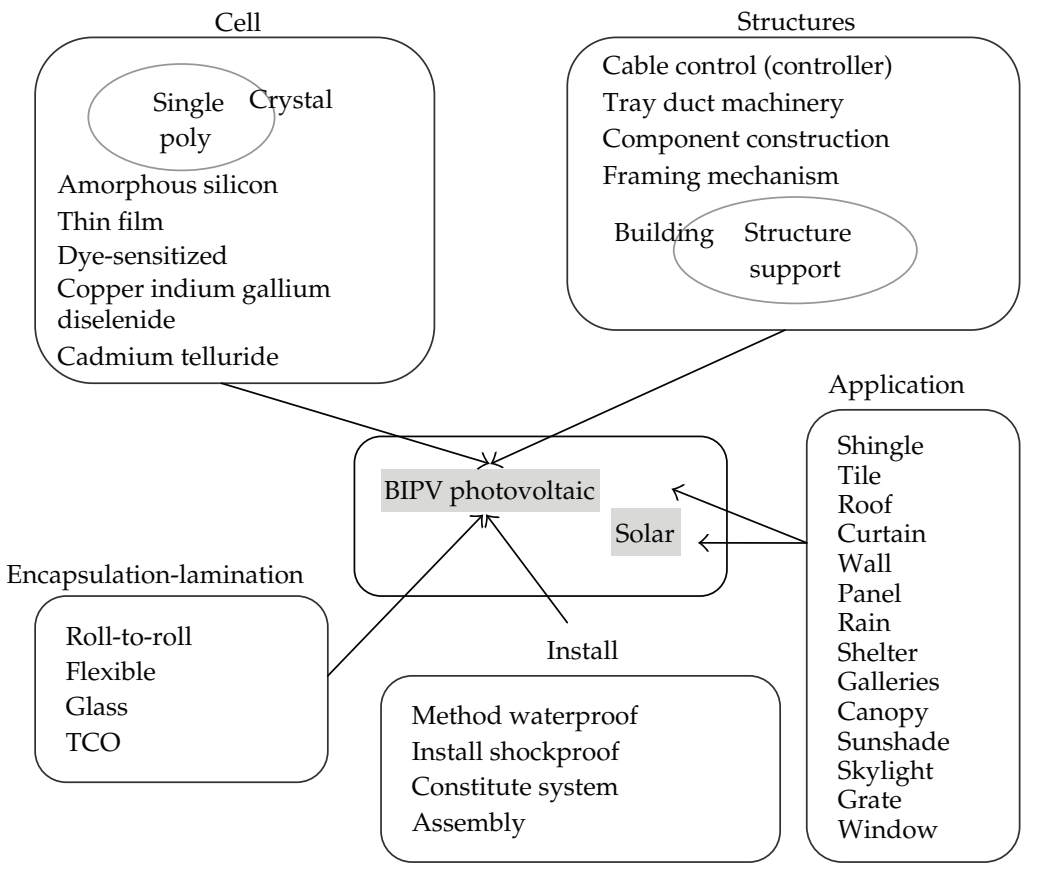

Figure 5: Keywords pool of BIPV.

\subsection{Patent Map}

The main purpose of a patent map is easy and effective understanding of patent information and analysis on a wide range of complex data and to represent them through measures such as tables or schemata. Figure 6 explains the process and related information of the patent map.

\subsection{Matrix Map}

A matrix map is two-dimensional array, and the array matrix is a simple data structure. Twodimensional array is by $x, y$ two-axial plane, and we can construct a spatial distribution of the state that through the display of the spatial distribution can clearly see the correlation 


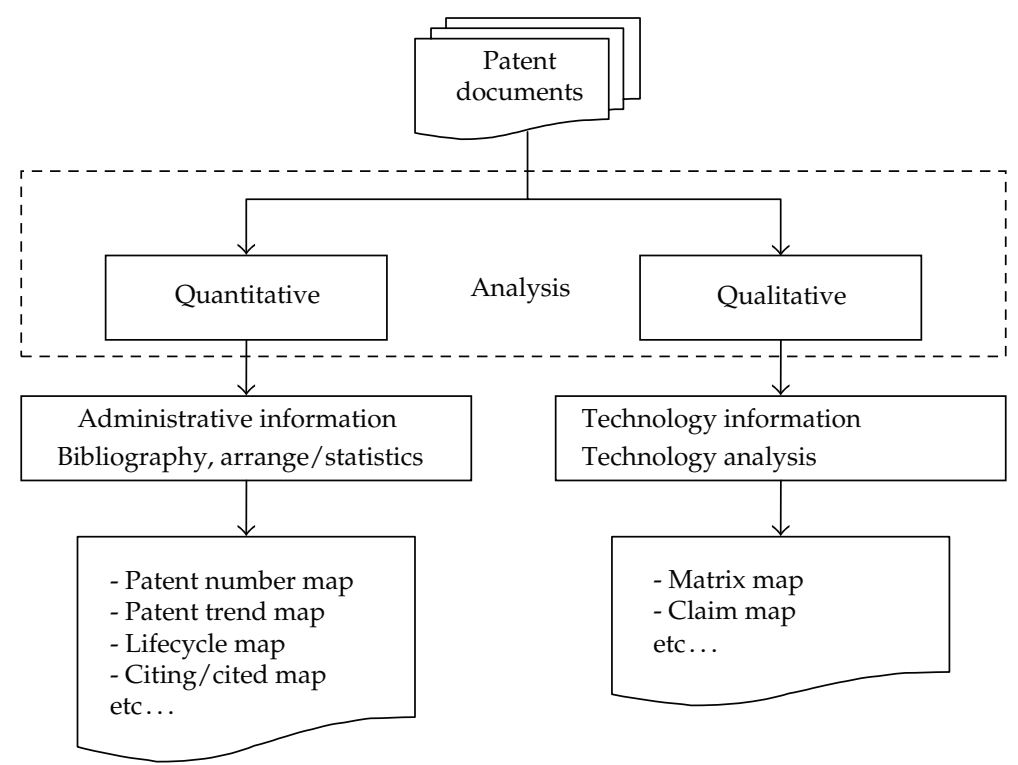

Figure 6: The process of patent map.

between the $x$-axis items with the $y$-axis items and the trends. Therefore, we can understand the relationship of its elements and functions in a two-dimensional array matrix notation as shown in Table 1. This study uses this two-dimensional array matrix to represent the technology function matrix, as shown in Table 2. A matrix map shows patent intelligence with the correlation between technical information, including technology sort and purpose sort. The matrix can be used to teach important technology and development trends. Therefore, R\&D managers can use patent matrix maps to develop related technologies and preventive strategies.

\subsection{Logistic Growth Model}

The study supposes technology growth with the property of $S$-curve. We adopt the Loglet Lab 2 , which is a kind of analysis software developed by Rockefeller University in 1994. There is a great advantage in setting all the parameters related to time series into analysis and the result presents as an S-curve [22]. S-curve can be classified into two types of symmetry and unsymmetry. The symmetry type represents the growth curve with inflection point, which can be presumed by the following equation:

$$
P(t)=\frac{k}{1+e^{-\alpha(t-\beta)}},
$$

where $P(t)$ means the patent numbers change with the time $t$; $\alpha$ means the slope (growth rate) of $S$-curve; $\beta$ means the inflection point of growth, which is the turning point of time spent into technique; $k$ means the saturation level of growth; $e$ means nature log. Based on the practice consideration, $[k * 10 \%, k * 90 \%]$ is defined as the growth interval. The period time from $10 \%$ of technology with maximum utility value to $90 \%$ presents by $\Delta t$. To proper 
Table 1: Arrays of two dimensions.

\begin{tabular}{cccccccc}
\hline & & \multicolumn{5}{c}{ Row-Major } \\
& $m$ & $R_{1}$ & $R_{2}$ & $R_{3}$ & $\ldots$ & $\ldots$ & $R_{n}$ \\
\hline \multirow{4}{*}{ Column-Major } & $C_{1}$ & $Q[1][1]$ & $Q[1][2]$ & $Q[1][3]$ & $\ldots$ & $\ldots$ & $Q[1][n]$ \\
& $C_{2}$ & $Q[2][1]$ & $Q[2][2]$ & $Q[2][3]$ & $\ldots$ & $\ldots$ & $Q[2][n]$ \\
& $C_{3}$ & $Q[3][1]$ & $Q[3][2]$ & $Q[3][3]$ & $\ldots$ & $\ldots$ & $Q[3][n]$ \\
& $\vdots$ & $\vdots$ & $\vdots$ & $\vdots$ & $\vdots$ & $\vdots$ & $\vdots$ \\
& $C_{m}$ & $Q[m][1]$ & $Q[m][2]$ & $Q[m][3]$ & $\ldots$ & $\ldots$ & $Q[m][n]$ \\
\hline
\end{tabular}

Table 2: Matrix map of patent.

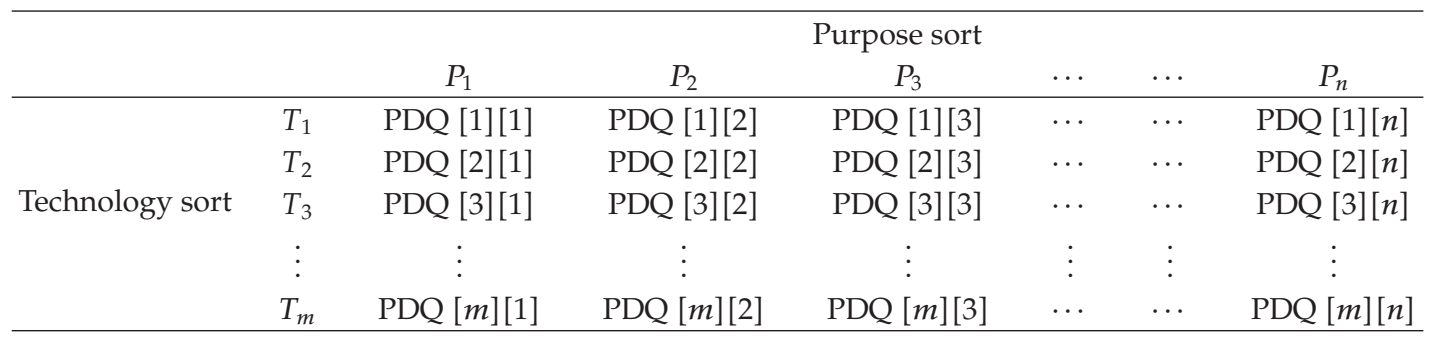

Notes: PDQ (patent document quantity).

represent the growth process and make it with more fitness, $\alpha$ is replaced by (3.2) in practice [23]. Therefore, the $P(t)$ is proposed as (3.3) as follows:

$$
\begin{gathered}
\Delta t=\frac{\ln 81}{\alpha}, \\
P(t)=\frac{k}{1+e^{\left[-(\ln 81 / \Delta t)-\left(t-t_{m}\right)\right]}} .
\end{gathered}
$$

This research is through the BIPV technology growth model calculation and describe technical development trend.

\section{BIPV Technology Development}

This model of research in technology forecasting and strategy for research and development is under construction by the world's major advanced countries such as the United States, Japan, and Germany, plus positive development of a PV industry in China. The BIPV technology and applications are as the empirical techniques in the study.

\subsection{Patent Map Analysis}

Using the keyword pool to begin the patent searching based on USPTO database, the date from the BIPV technology patents in the field of data begins on July 26, 1977 and runs to October 31, 2011. Through the patent searching process, results of 263 valid patents in this study are obtained. The results of patent numbers in every year and accumulative patent 


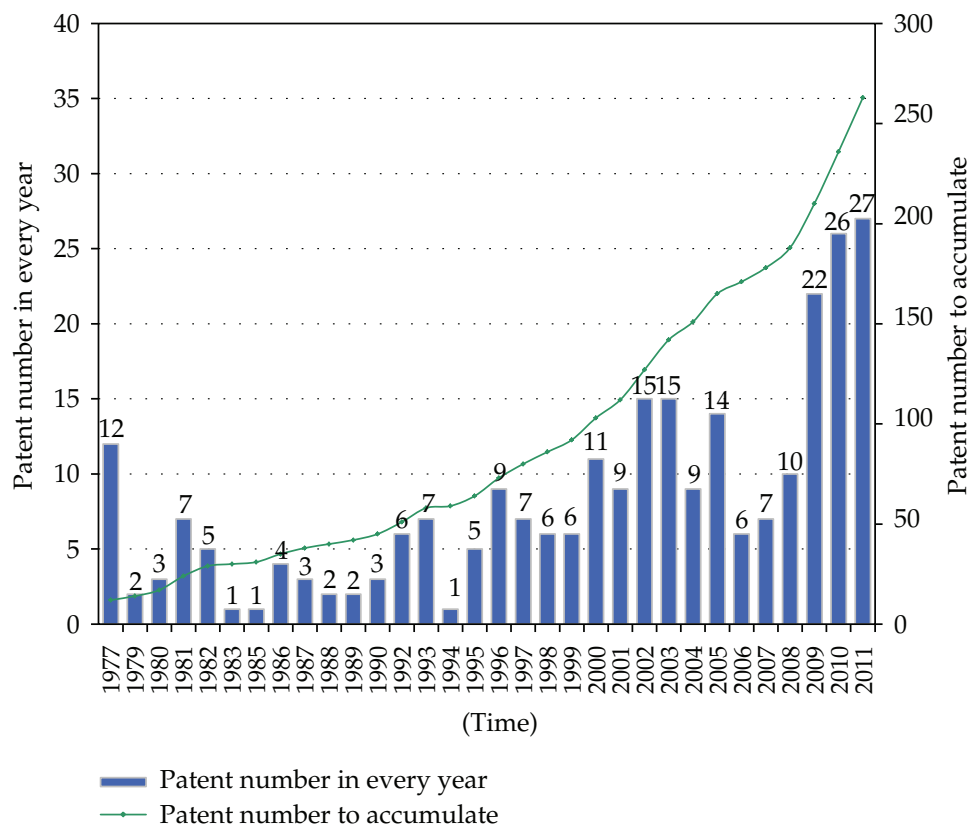

Figure 7: Patent number and accumulative numbers of BIPV.

numbers are shown in Figure 7. Global warming and near-future energy crisis results show an increase in related patents since early 2000.

Analyzing the number of patents for technology, purpose, and application (Figure 8) can determine the BIPV technology development level of a country. The patent output of United States (US) is the first; Japan (JP) is the second. Germany (DE) accounted for approximately 5\% of BIPV technology in Europe. Results show that countries most focused on R\&D of BIPV technology are the United States, Japan, and Germany.

Results of the firm-level analysis show major manufacturers and product applications. Table 3 shows PV module technology directions and strategies in the BIPV industry. The table shows that most manufacturers continue developing roof technology and its applications. However, some manufacturers have changed $R \& D$ strategies to focus on glass curtain walls and external walls.

\subsection{Matrix Map}

The results of technology effect analysis, the matrix map is shown in Figure 9. According to the complex BIPV technology, we can classify the functions into two groups: main function and subfunction. The main functions of BIPV are generating electric, building materials to diversify quality and reliability, install and maintain, and keeping cost down. The main function map presents the development of BIPV from 1977 to 2011. A larger pie chart means a large number of patents and represents the technology development center. On the contrary, a smaller pie chart means fewer patents, which is worthy of note by research and development personnel. BIPV derives technologies corresponding to the early functions in the field of 


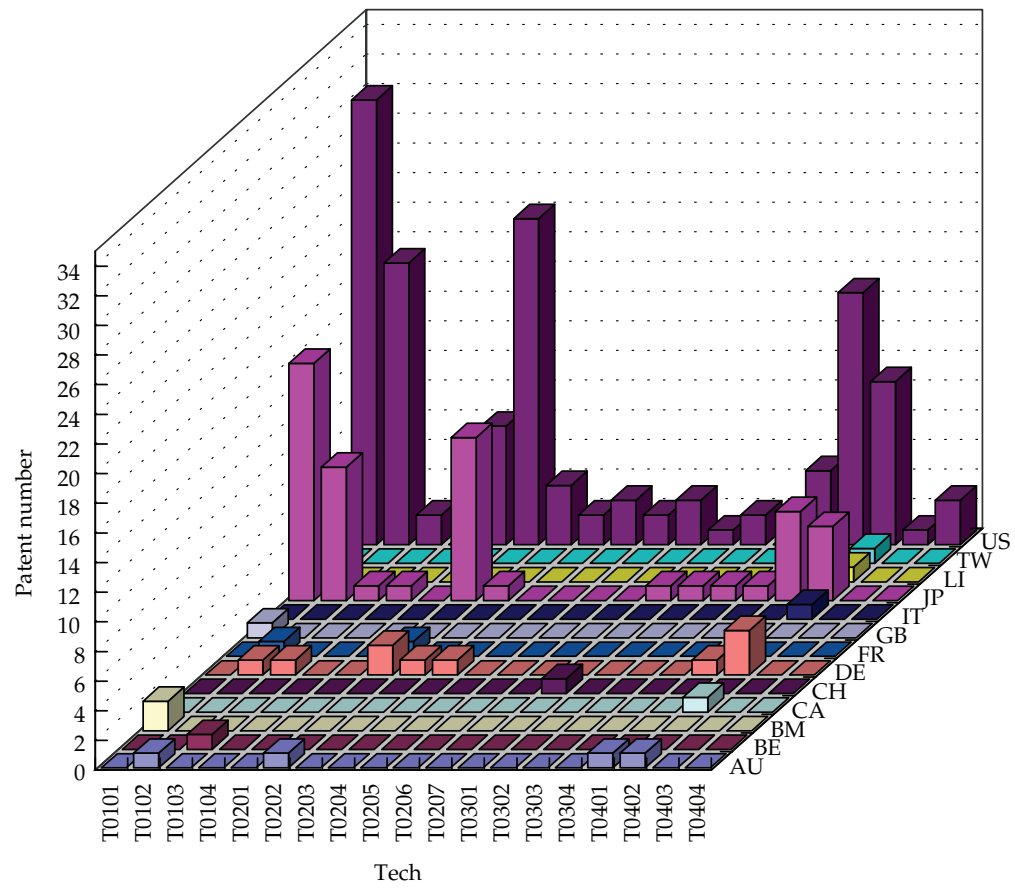

(a) The number of patents in the focus on technology

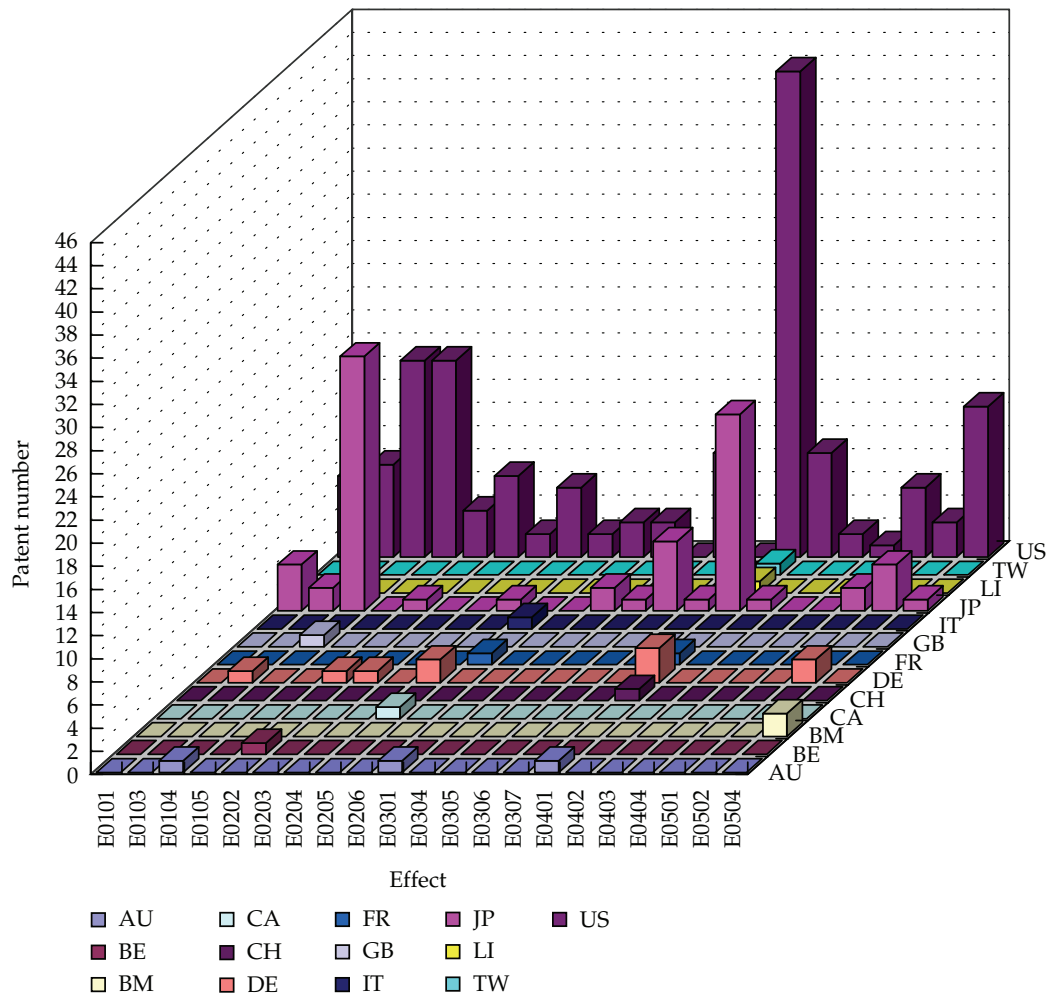

(b) The number of patents in the focus on the purpose

Figure 8: Continued. 


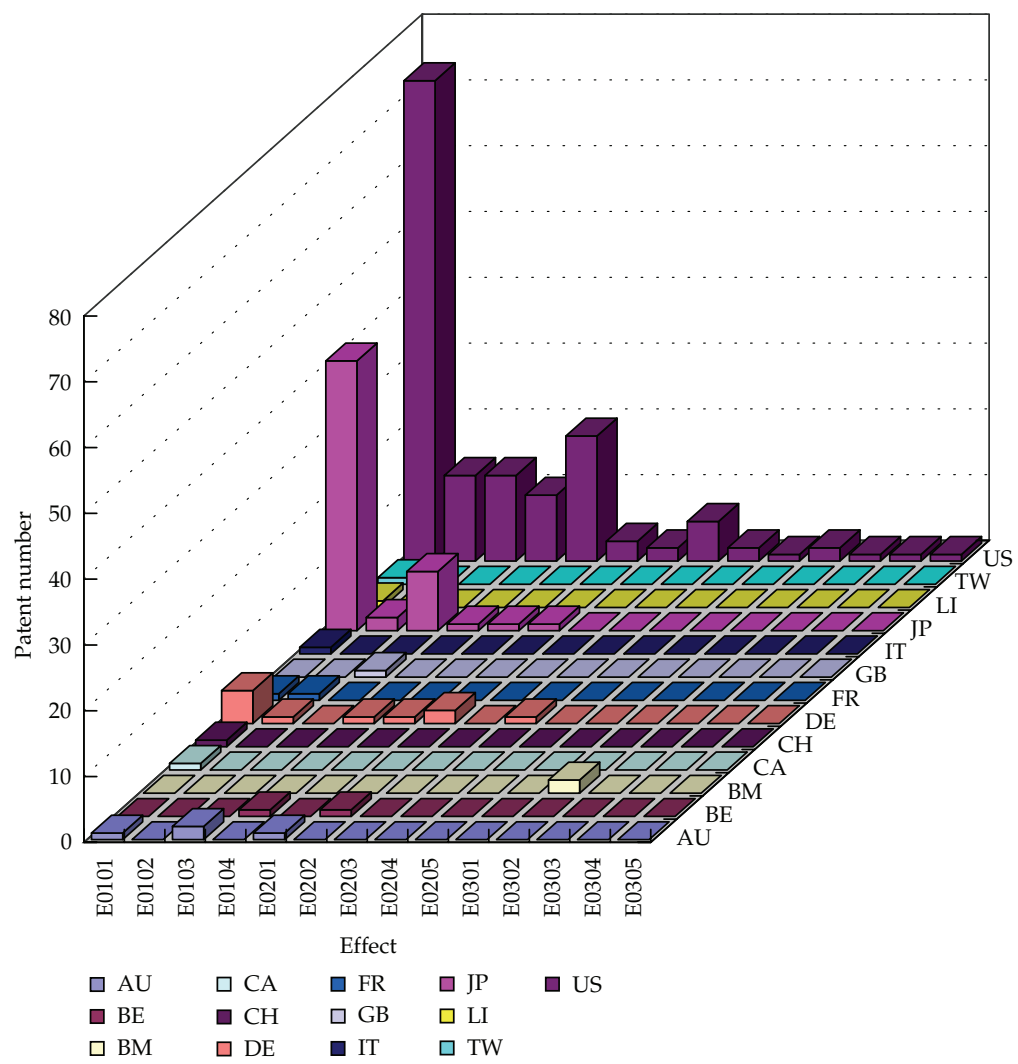

(c) The number of patents in the focus on the application

Figure 8: BIPV technology three-dimensional (technology, purpose, and application) map in country level.

Table 3: BIPV manufacturers and product applications.

\begin{tabular}{|c|c|c|c|}
\hline Manufacturer & Country & Product name & Application \\
\hline \multirow{4}{*}{ Uni-solar } & \multirow{4}{*}{ US } & Photovoltaic Laminate & Various shapes of roofs in commercial buildings \\
\hline & & Power Tilt & The flat roofs in commercial buildings \\
\hline & & EnerGen & Residential roofs \\
\hline & & PowerShingle & Residential roofs \\
\hline Power Film Solar & US & N/A & Commercial building roof \\
\hline First Solar & US & $\mathrm{N} / \mathrm{A}$ & Commercial building roof \\
\hline Ascent Solar & US & WaveSol & Roof \\
\hline $\begin{array}{l}\text { Global Solar } \\
\text { Energy }\end{array}$ & US & Power FLEX & Roof \\
\hline Solyndra & US & $100 / 200$ series & Commercial building roof \\
\hline Konarka & US & Power Plastic & Roofs and external walls \\
\hline \multirow{2}{*}{ Sharp } & \multirow{2}{*}{$\mathrm{JP}$} & ND/NU series & Roof \\
\hline & & NA series & Roofs and external walls \\
\hline \multirow{3}{*}{ Kaneka Solartech } & \multirow{3}{*}{$\mathrm{JP}$} & Hybrid silicon & Roof \\
\hline & & $\begin{array}{l}\text { SOLTILEX, VISOLA, } \\
\text { GRANSOLA }\end{array}$ & Tile style roof in a residential \\
\hline & & See-Through & Glass curtain wall \\
\hline Honda Soltec & $\mathrm{JP}$ & HEM series & Roof \\
\hline Würth Solar & $\mathrm{DE}$ & GeneCIS series & Roofs and external walls \\
\hline Dyesol & $\mathrm{AU}$ & Sun2 & Roofs and external walls \\
\hline
\end{tabular}




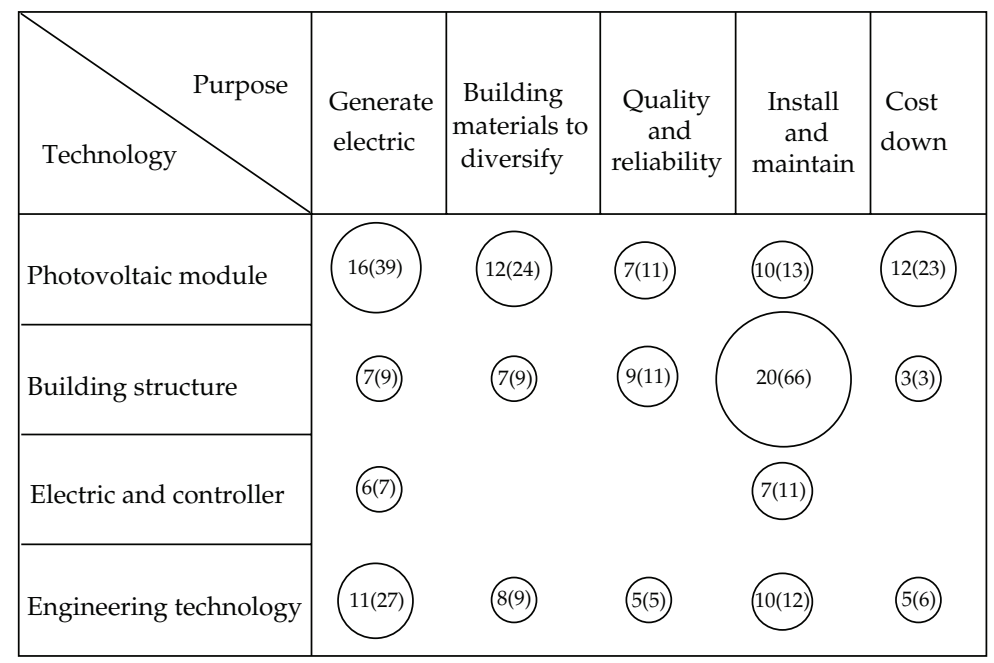

Figure 9: Main purpose matrix map of BIPV. $Y(Q)$ : patent number of years (in accordance with this technology and the effectiveness of patent). The pie chart represents the number of patents. Patent number of the more means larger the pie chart, and vice versa smaller.

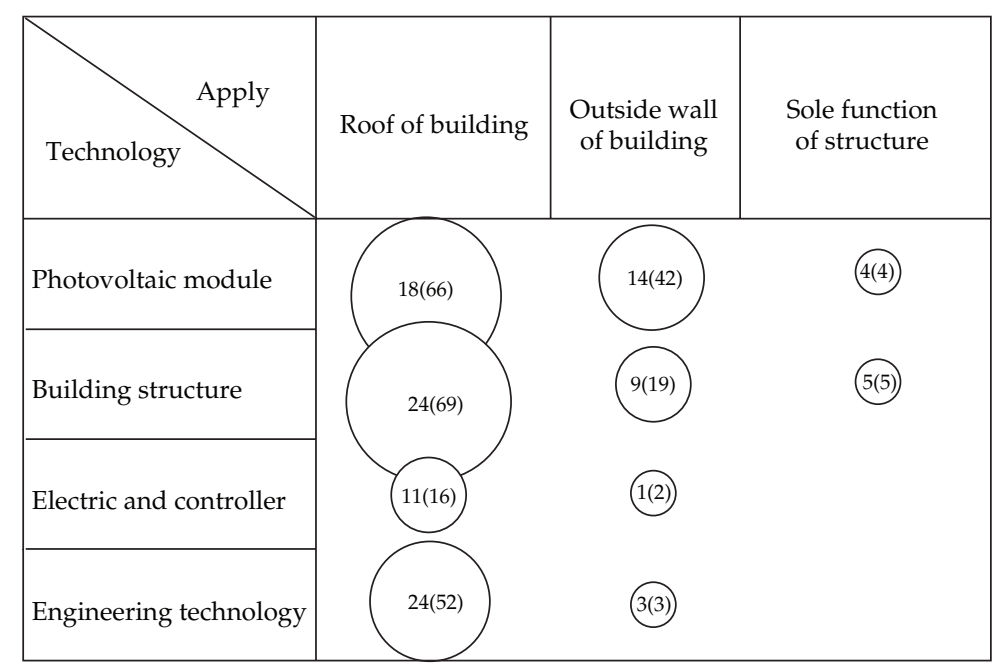

Figure 10: Main apply matrix map of BIPV. $Y(Q)$ : patent number of years (in accordance with this technology and the effectiveness of patent). The pie chart represents the number of patents. Patent number of the more means larger the pie chart, and vice versa smaller.

technology development from 1977 to 2011 . The technical function matrix gives a more precise formulation of the future direction of development policy.

We can understand the technology development trends by analyzing the effect of the technology and the application of BIPV. After further study through a combination of two oriented analyses, we will be better able to judge technology trends and liquidity phenomena. According to technology mapping from 1977 to 2011, the main applications of BIPV are in the roof of the building (Figure 10), especially in USPTO patent pieces in the United States, Japan, and Germany. 


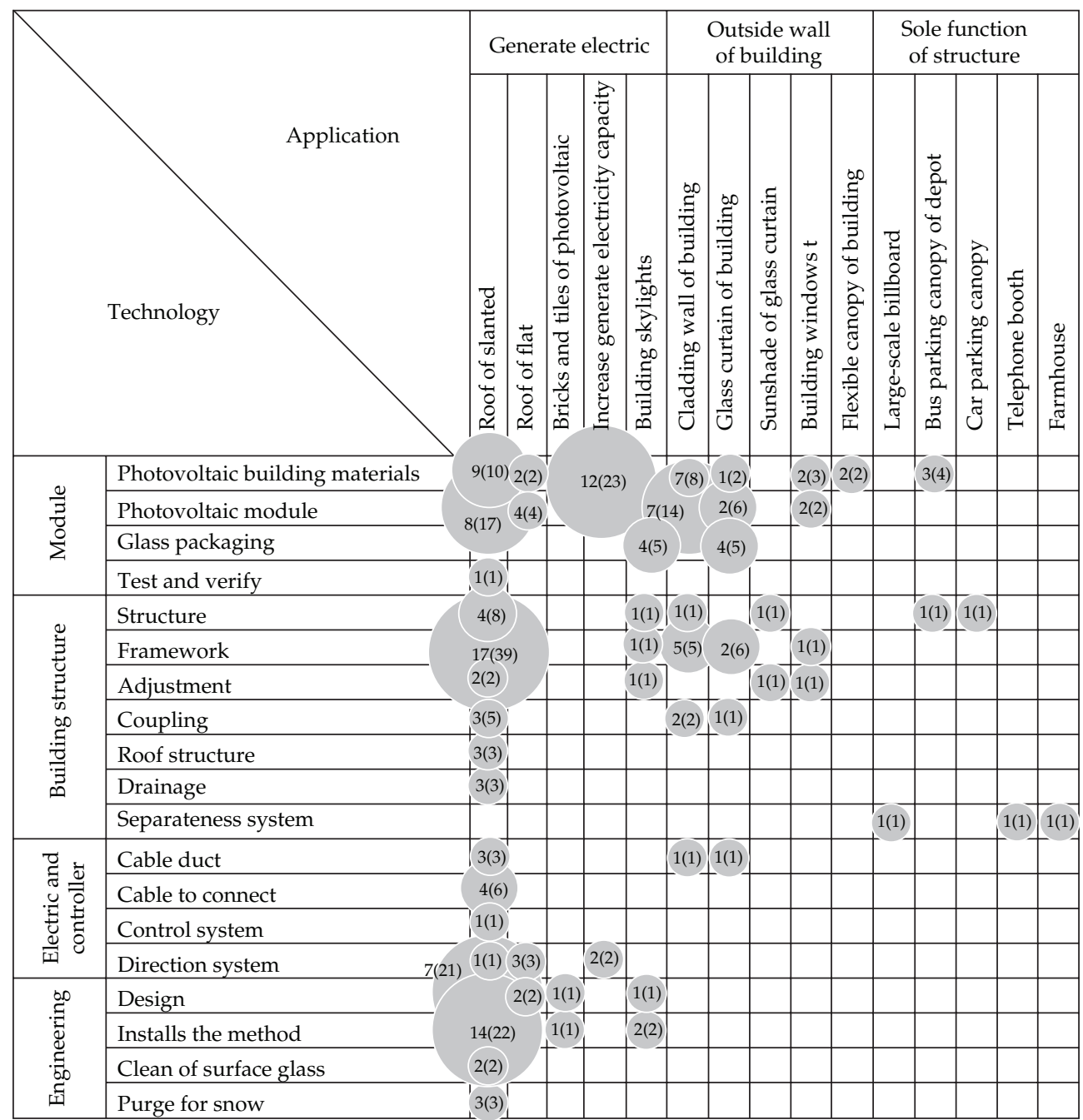

Figure 11: Subapplication matrix map of BIPV. $Y(Q)$ : patent number of years (in accordance with this technology and the effectiveness of patent). The pie chart represents the number of patents. Patent number of the more means larger the pie chart, and vice versa smaller.

Due to high latitudes, the technology development is mainly to oblique roof. We also can find out technology application and purpose in the field of BIPV technology development by Figures 11 and 12. The subtechnology matrix can provide more accurate positioning and development of the strategic direction of future research and development.

We can use dynamic trend analysis, technology research, and development activities to watch the technology development of the whole picture through patent maps. The crossanalysis by purpose and applications of technology can help us to grasp the accurate R\&D direction.

After analyzing the technology purpose and application matrix map, it was combined with time to show the evolution of BIPV purposes and applications over time. This study proposes a patent number weight over time concept. In Figure 13, there are five major purposes of BIPV technology on the $x$-axis and three major applications of BIPV technology 


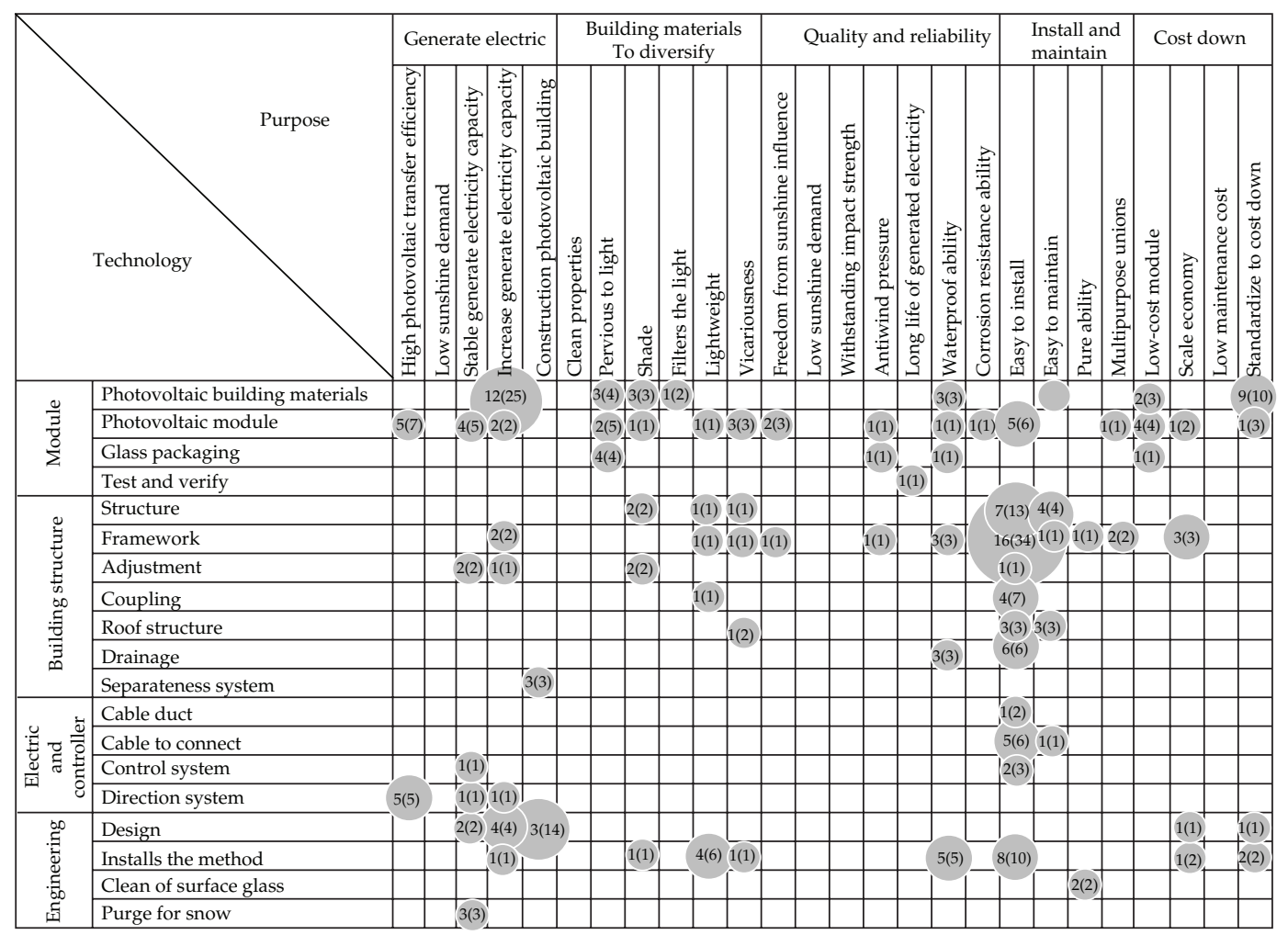

Figure 12: Subpurpose matrix map of BIPV. $Y(Q)$ : patent number of years (in accordance with this technology and the effectiveness of patent). The pie chart represents the number of patents. Patent number of the more means larger the pie chart, and vice versa smaller.

on the $y$-axis. Over three periods $\left(s_{1}-s_{3}\right)$, the growth in patent number weights of outside wall building materials and the installation and maintenance of solar panels can be identified. The patent number weights include technical application and purpose over three periods. Technical purposes include electricity generation, diversified building materials, quality and reliability, installation and maintenance, and cost reduction. Technical applications are structure function, outside building wall, and building roof. The weights for the technical purpose and application of the patent number are calculated using (4.1):

$$
\begin{aligned}
& w_{x_{i}, s_{j}}=\frac{p_{x_{i}, s_{j}}}{\sum_{i=1}^{m} p_{x_{i}, s_{j}}} \times 100 \% \\
& w_{y_{i}, s_{j}}=\frac{p_{y_{i}, s_{j}}}{\sum_{i=1}^{n} p_{y_{i}, s_{j}}} \times 100 \%,
\end{aligned}
$$

where $w_{x_{i}, s_{j}}$ is the patent number weight for different technical purposes $\left(x_{i}\right)$ in a different stage $\left(s_{j}\right) \cdot p_{x_{i}, s_{j}}$ is the patent number for different technical purposes $\left(x_{i}\right)$ in a different stage $\left(s_{j}\right) . w_{y_{i}, s_{j}}$ is the patent number weight for different technical applications $\left(y_{i}\right)$ in a different stage $\left(s_{j}\right) \cdot p_{y_{i}, s_{j}}$ is the patent number for different technical purposes $\left(y_{i}\right)$ in a different stage $\left(s_{j}\right)$. 


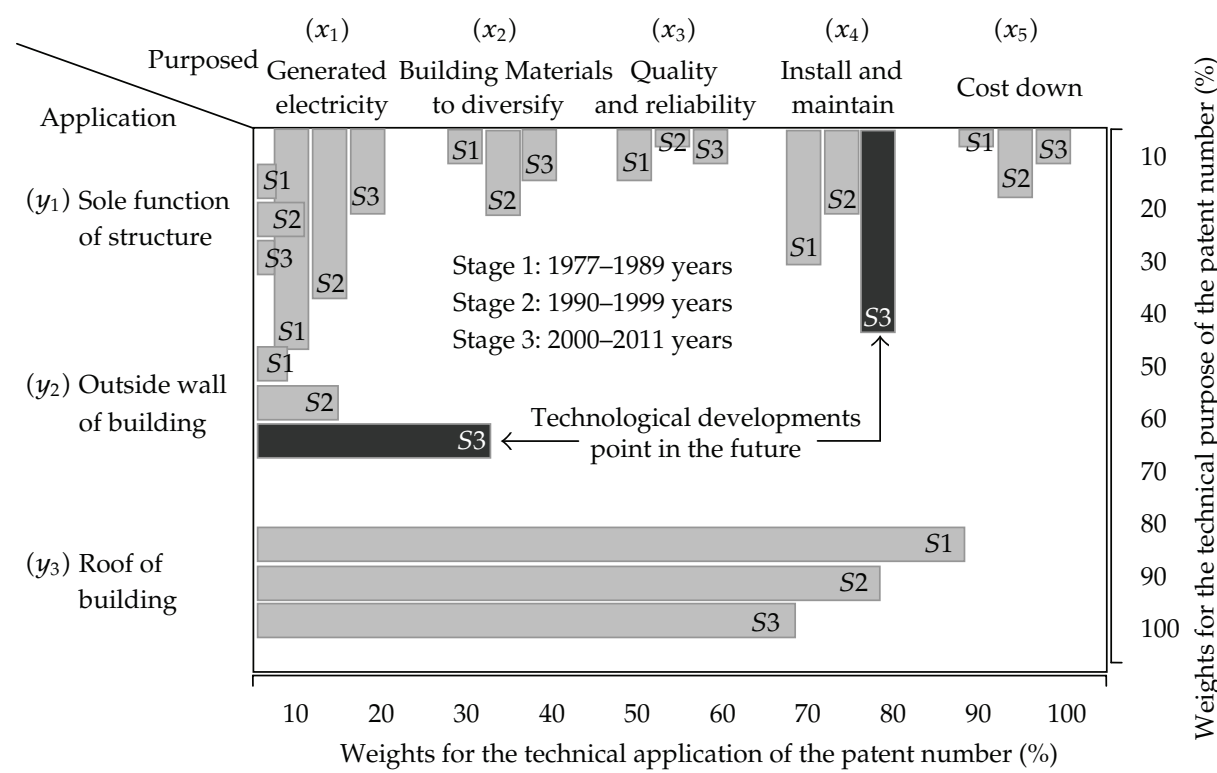

Figure 13: BIPV technology development trends.

The objective of installation and maintenance is to ensure that diverse building materials in the outside walls of high-rise buildings are of high quality and reliable. The technical purpose weights of the number of diverse building material patents are low (Figure 14). Other than R\&D into photovoltaic panels, they emphasize future methods of engineering and installing photovoltaic panels on the outside walls of high-rise buildings. However, safety and durability must be considered when developing diverse building materials. Indoor comfort must be considered when installing and maintaining buildings because people are central to BIPV. Key BIPV R\&D factors are insulation, daylight penetration, visual appeal, wind and rain proof, earthquake proof, fireproof, national technical building regulations, compliance with building rules, and compliance with construction material tests (Figure 15 and Table 4).

\subsection{Technology Forecasting: Logistic Growth}

This study uses Loglet Lab developed by Jason Yung, Perrin S. Meyer, and Jesse Ausubel as a tool to predict future development of BIPV technology trends. Technology start time, transition time, and saturation time are shown through the S-curve to depict the message (Figure 16). Up to October 31, 2011, a total of 263 pen announcement patents were approved by the USPTO patent database since July 26,1977 . The logistic growth curve diagram shows the technical saturation point for the 1881 patents. Defined according to the value of $k$ $[k \times 10 \%, k \times 90 \%]$, it corresponds to the growth point in time in February 2008. The turning point from growth to maturity is in January 2032. To close to $90 \%$ saturation point in time through the system to calculate the growth time of 49.4 years in June 2057, its BIPV technology patent saturation point is about 1881 cumulative patents. From the phenomenon of technology development at the application level, many patents focus on roof of building. However, the number of patents in the outside wall of building applications has grown well above the roof of building. This means that focus has moved to outside wall of building 


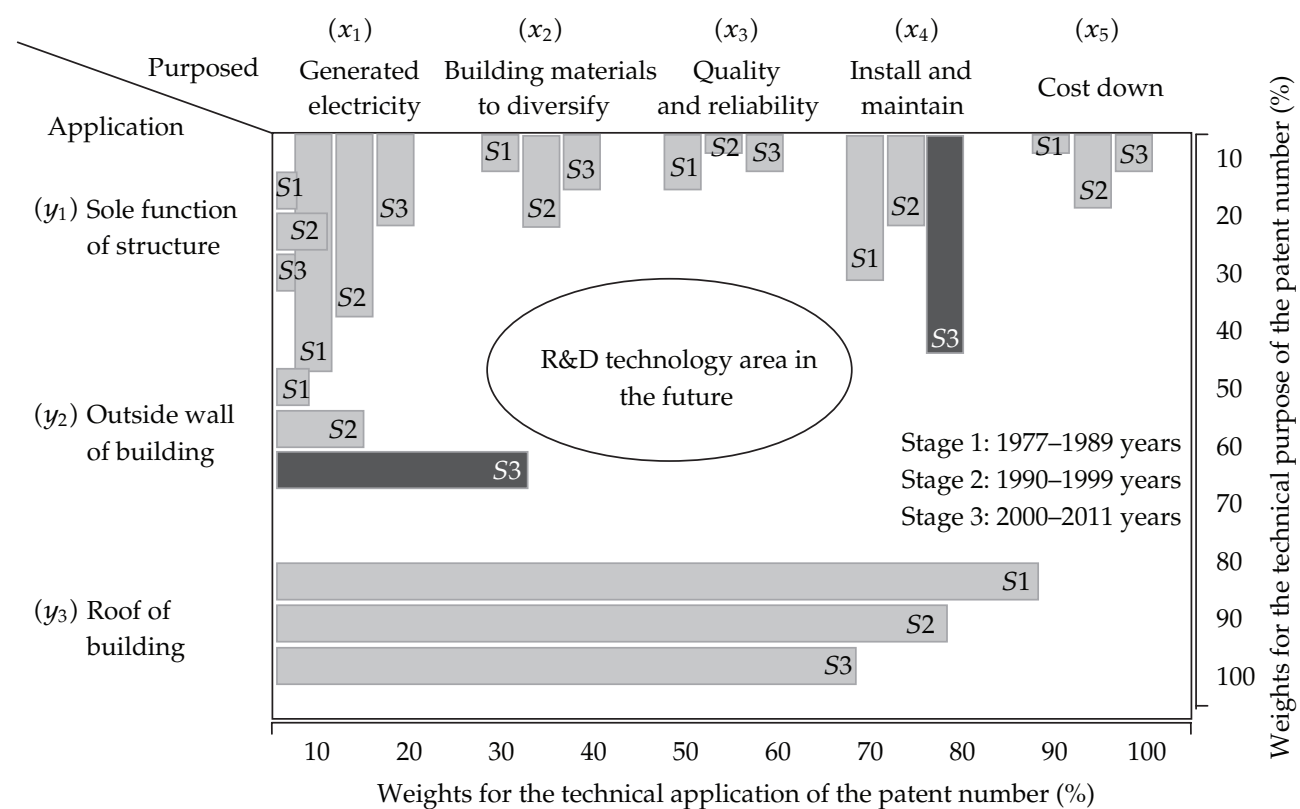

Figure 14: BIPV technology R\&D areas in the future.

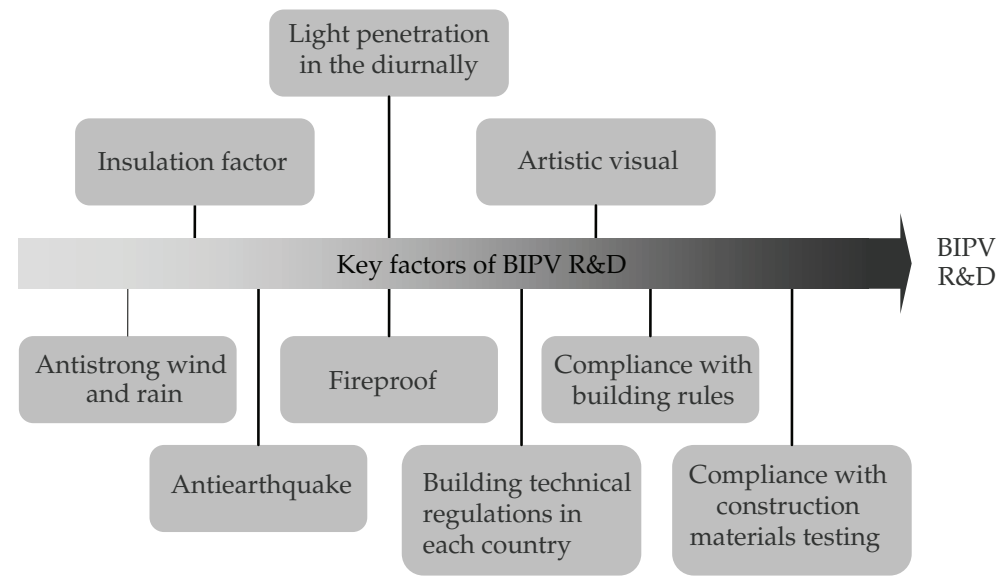

Figure 15: Key factors of BIPV R\&D.

technology development. Therefore, this field of research for BIPV technology is in line with the number of patents in the outside wall of building development trend forecast in this study (Figure 17). Through the logistic growth, the curve graph shows the technical saturation point for the 449 patents. Defined according to the value of $k,[k \times 10 \%, k \times 90 \%]$ corresponds to the growth point in time, in February 2010. The turning point from growth to maturity is in January 2022. To close to $90 \%$ saturation point in time through the system to calculate the growth time of 23.6 years in August 2033, its BIPV technology patent saturation point about cumulative to 449 patents. 
Table 4: The definition of the key factors of BIPV development.

\begin{tabular}{ll}
\hline Key factor & Definition \\
\hline Insulation & $\begin{array}{l}\text { Block thermal radiation heat from the sun and reduce } \\
\text { indoor heat loads }\end{array}$ \\
\hline Daylight penetration & $\begin{array}{l}\text { Increase PV module light penetration and reduce interior } \\
\text { lighting power demands }\end{array}$ \\
\hline Artistic visual & $\begin{array}{l}\text { PV fusion of the exterior of a building improves architec- } \\
\text { tural aesthetics }\end{array}$ \\
\hline Antistrong wind and rain & $\begin{array}{l}\text { Resistant to strong wind and rain, thereby increasing } \\
\text { building security }\end{array}$ \\
\hline Antiearthquake & $\begin{array}{l}\text { Resistant to earthquakes, thereby increasing building } \\
\text { security }\end{array}$ \\
\hline Fireproof & $\begin{array}{l}\text { Resistant to fire, avoiding fire spreading from inside a } \\
\text { building to adjacent buildings and avoiding external fires } \\
\text { spreading inside }\end{array}$ \\
\hline National technical building regulations & Must comply with national standards \\
\hline Compliance with building rules & Must comply with construction technique rules \\
\hline Compliance with construction material tests & \begin{tabular}{l} 
Must comply with specifications for inspection and testing \\
\hline
\end{tabular}
\end{tabular}

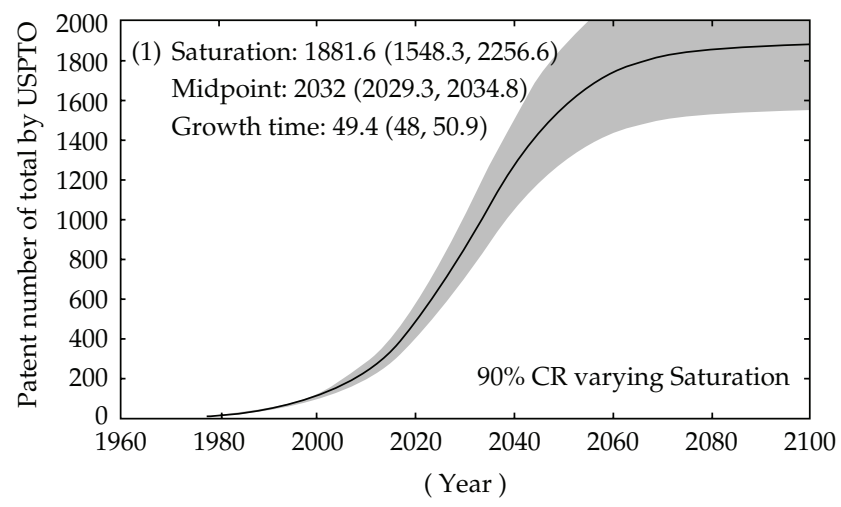

Figure 16: Technology growth curve of BIPV.

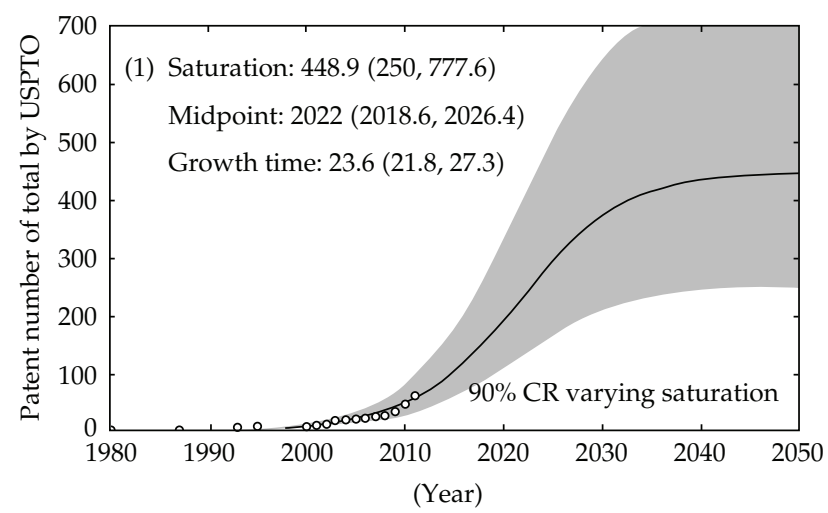

Figure 17: Technology growth curve of BIPV for outside wall of building. 
Table 5: Life cycle phases of BIPV.

\begin{tabular}{lcccc}
\hline Life cycle & Introductory stage & Growth stage & Maturity stage & Saturation stage \\
\hline Beginning time & 1977.07 & 2008.02 & 2032.01 & 2057.06 \\
\hline
\end{tabular}

Table 6: Life cycle phases of BIPV on outside wall of building.

\begin{tabular}{lcccc}
\hline Life cycle & Introductory stage & Growth stage & Maturity stage & Saturation stage \\
\hline Beginning time & 1987.05 & 2010.02 & 2022.01 & 2033.08 \\
\hline
\end{tabular}

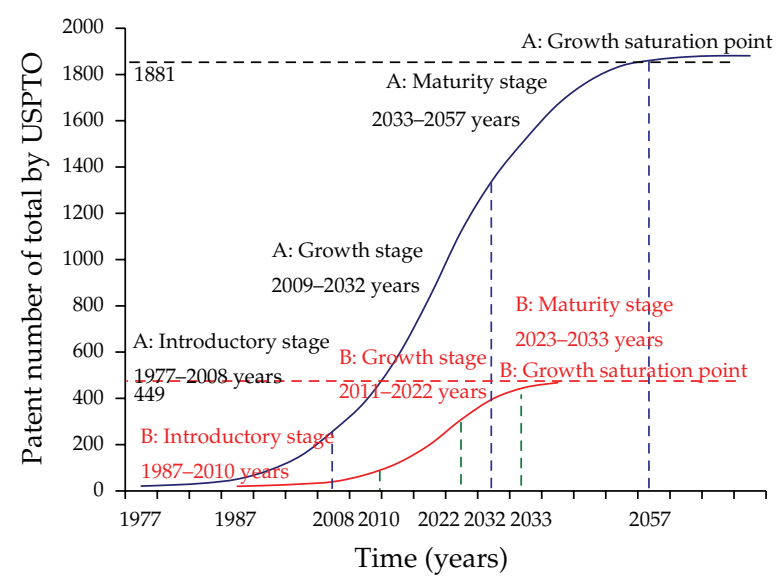

Figure 18: S-curve of BIPV. S-curve A: BIPV technology develop forecasting. S-curve B: BIPV on outside wall of building technology develop forecasting.

By Loglet Lab statistics describing logistic growth curve diagram out BIPV technology life cycle in Table 5 and BIPV technology application in the outside wall of building development of the technology life cycle in Table 6.

Figure 18 shows the BIPV technology $S$-curve. S-curve A refers to BIPV technology developing forecasting, and S-curve B refers to BIPV outside wall building technology developing forecasting. S-curve A shows that the introductory BIPV stage was from 1977 to 2008; the growth stage is from 2009 to 2032; the maturity stage is from 2033 to 2057; the growth saturation point is near 2057. S-curve B shows that the introductory stage of BIPV outside wall building technology was from 1987 to 2010; the growth stage is from 2011 to 2022; the maturity stage is from 2023 to 2033; the growth saturation point is near 2033.

\section{R\&D Strategy}

BIPV technology functions through the research and technical application of matrix state space dimensions, combined with the logistic growth curve that takes on a timeline surface. It shows BIPV technology patents in the field focused on the building roof assembly and installation techniques and applications. In the vertical plane of buildings, the technology and application of patents clearly show the phenomenon of loose or blank. This one-block technology for three-dimensional space of the buildings shows the use of maximum power generation area in the world's major countries to actively develop the future generation of 
Table 7: BIPV technology key point in the future.

\begin{tabular}{ll}
\hline Technology node & Description \\
\hline Durability & When PV modules are used in construction, the difference between the PV \\
module and the building lifespan must be considered. The life of an average \\
building is more than several decades or even centuries, but the life of a PV \\
module is only 10-20 years. Therefore, in addition to enhancing photoelectric \\
conversion efficiency, PV module durability should be a major focus in the future
\end{tabular}

Table 8: Matrix of R\&D strategy.

\begin{tabular}{ccccl}
\hline $\begin{array}{l}\text { Degree of } \\
\text { protection capability } \\
\text { R\&D } \\
\text { creation }\end{array}$ & $\begin{array}{l}\text { Benefit } \\
\text { strategy }\end{array}$ & Description \\
\hline $\mathrm{H}$ & $\mathrm{H}$ & $\mathrm{L}$ & Attacker & $\begin{array}{l}\text { Actively to the goal of Sheep to obtain royalty patent } \\
\text { portfolio through intensive construction }\end{array}$ \\
\hline $\mathrm{H}$ & $\mathrm{L}$ & $\mathrm{H}$ & Stalker & $\begin{array}{l}\text { The patent with high-strength and high-product ben- } \\
\text { efits usually adopt a cross-licensing model and other } \\
\text { competitors to obtain the balance of terror }\end{array}$ \\
\hline $\mathrm{protection}$ products and the other can sue the other \\
party infringement strategy \\
\hline $\mathrm{L}$
\end{tabular}


low-energy buildings. With technological development of a new generation of low-energy buildings, researchers also can evade patents in the patent radar district and also can compare the similarities and differences through analysis and interpretation of the patent information for reverse engineering in order to find a niche cut into the conducting dig technology policy. In addition, vertical walls of BIPV technology for space technology to divide policies are found in the lower reaches of this technology on the chain of a key, and that node is full of patent as long as the technology vendor in this field must go through this technology node (Table 7) and must pay patent royalties for different strategies.

Technology research and development policy is often associated with the market environment and technical ability having a close relationship. Technical developments, in particular in the early development of BIPV, through a technology growth curve that still has a long development time, and BIPV technology are the future of new generations of low buildings. Annual energy output of high technology and reduced costs to obtain construction and low construction investment for technology development and market factors continue. Therefore, enterprise technology products developed simultaneously must consider technology research and development capabilities, patent protection, and creating patent interest to locate the future development strategy of the three factors.

However, enterprises in competitive markets must improve manpower, time, and resources to maintain the technological lead. Technological backwardness of a company or country must be to narrow the distance with the technology leader in technology R\&D and innovation. If companies want to enhance overall competitiveness, they must first assess their own abilities (including R\&D personnel, capital, and the ability to create benefits and protect patents) and then, according to the size of the business and its abilities, select suitable R\&D strategies. This study provides a three-dimensional matrix (Table 8) of degree of protection, $R \& D$ capability, and benefit creation to select $R \& D$ strategies. The first assessment indicator is the intensity of innovative R\&D and the degree of patent protection. The second assessment indicator is the R\&D capability of an enterprise with $R \& D$ manpower and resources. The third assessment indicator is the ability of an enterprise to create benefits using technology. This assessment method proposes eight strategies to assist an enterprise in locating their future R\&D strategy when conducting BIPV technology R\&D.

The results (Figures 13, 14, and 15) show that BIPV development moves gradually from roofs to outside walls or glass curtain walls. If companies want to produce a BIPV technology patent portfolio, they can use the three-dimensional matrix to assess and select a suitable R\&D strategy according to individual enterprise circumstances. They can also use the patent map from this study to understand key high-intensity factor technologies for strategic actions to build important technology paths and patent intensity to increase profitability.

\section{The Future Work of BIPV Industry}

The results show that the BIPV industry is experiencing rapid growth and technology R\&D. However, the BIPV manufacturing industry faces global competitive pressures, and the following characteristics can assist future development of the BIPV industry.

(1) Low installation costs: because of different factors such as global economic conditions, the built environment, and landscape, balancing the regional economic environment and technology is important for the BIPV industry;

(2) diversification of building materials: materials must be lightweight and fit building exteriors. PV modules must meet the requirements of different buildings, high 
security and reliability, unique color, and pattern change while maintaining high photoelectric conversion efficiency. This enhances market appeal;

(3) amorphous silicon solar-cell efficiency: amorphous silicon thin-film solar-cell modules can be bent and absorb diffuse light to produce electrical energy characteristics. These advantages are not matched by silicon solar-cell modules. Amorphous silicon thin-film solar-cell module use in the BIPV industry is small. However, power generation efficiency of amorphous silicon thin-film solar-cell modules is less than that of silicon solar-cell modules. In the future solar-cell market, silicon solar-cell modules will remain the main market, but amorphous silicon thin-film solar-cell modules will continue to grow. Therefore, enhancing the photoelectric conversion efficiency of amorphous silicon thin-film solar-cell modules should be a BIPV industry priority;

(4) strategic integration of industry groups: to continually improve BIPV market attractiveness and reduce manufacturing costs, the BIPV industry must integrate the PV, construction, and electromechanical industries to form an industrial group. Active industrial and technical cooperation can promote and enhance the BIPV industry for future development;

(5) import green building materials: as government subsidy policies gradually decrease, subsidies will no longer affect BIPV market development. Future BIPV technology development must be combined with the concept of green buildings and comply with building material specifications. Making BIPV products a part of green building materials is necessary for the future.

\section{Conclusions and Recommendations}

Due to the issue of global warming, the renewable energy technologies become more essential nowadays. The solar energy technology is concerned in the worldwide. Therefore, the interdisciplinary integration is an important trend. The building-integrated photovoltaic (BIPV) is an emerging technology integrating the photovoltaic and building fields. We are interested in the BIPV's development and aim to explore its evolution. From the perspective of patent analysis, this study hopes to offer some useful recommendations for BIPV's technology development. To explore life cycle of BIPV technology, we use logistic model analyzing patent numbers from the database of United States Patent and Trademark Office (USPTO).

We propose a hybrid approach in exploring the life cycle of BIPV technology and develop the R\&D strategies of related industry. The proposed approach comprises the following submodules. First, patent analysis is employed to transform patent documents into structured data. Second, the logistic growth model is used to explore the life cycle of BIPV technology. Third, patent matrix map analysis is used to develop the R\&D strategies of BIPV industry. Through the analysis by logistic model, the BIPV technology is expected a long-term life cycle from the emerging stage to the growth stage. The logistic results show the development of BIPV technology is growing fast since 2000 and still have development potential up to 2057.

The other important result is discovered in the three-dimensional matrix for $R \& D$ strategies in this paper. The three dimensions are R\&D capability, degree of protection, and benefit creation of patent. There are eight patent-portfolio strategies for BIPV industry. We 
think that the proposed model is useful for forecasting the trend of technology, especially in the field of BIPV. In the future, we hope it will also be applied in other technologies and industries.

\section{References}

[1] S. J. Liu and J. Shyu, "Strategic planning for technology development with patent analysis," International Journal of Technology Management, vol. 13, no. 5-6, pp. 661-680, 1997.

[2] J. L. Chen, S. J. Liu, and C. H. Tseng, "Technological innovation and strategy adaptation in the product life cycle," Technology Management: Strategies and Application, vol. 5, no. 3, pp. 183-202, 2000.

[3] S. Kuznets, "Innovative activity: problems of definition and measurement," in The Rate and Direction of Inventive Activity, R. Nelson, Ed., Princeton University Press, New Jersey, NY, USA, 1962.

[4] B. H. Hall, Z. Griliches, and J. A. Hausman, "Patents and R\&D: is there a lag?" International Economic Review, vol. 27, no. 2, pp. 265-283, 1986.

[5] H. Ernst, "The use of patent data for technological forecasting: the diffusion of CNC-technology in the machine tool industry," Small Business Economics, vol. 9, no. 4, pp. 361-381, 1997.

[6] S. B. Chang, Establishing two stages technological positions model: derived from the patent analysis of business method [Doctoral dissertation], National Yunlin University of Science and Technology, Yunlin, Taiwan, 2004.

[7] W. Barroso, L. Quoniam, and E. Pacheco, "Patents as technological information in Latin America," World Patent Information, vol. 31, no. 3, pp. 207-215, 2009.

[8] B. P. Abraham and S. D. Moitra, "Innovation assessment through patent analysis," Technovation, vol. 21, no. 4, pp. 245-252, 2001.

[9] H. Ernst, "Patenting strategies in the German mechanical engineering industry and their relationship to company performance," Technovation, vol. 15, no. 4, pp. 225-240, 1995.

[10] C. H. Guo, "Taiwan solar cell patent application for the current situation," Guang Lian: Guang Dian Chan Ye Ji Ji Shu Xue Bao, vol. 76, pp. 50-56, 2008 (Chinese).

[11] Y. B. Chen and X. Y. Cheng, "Solar cell patent analysis and development trends," in Proceedings of the ITRI Innovation and Technology Management Conference, pp. 1-8, 2006.

[12] A. G. Hu, "The regionalization of knowledge flows in East Asia: evidence from patent citations data," World Development, vol. 37, no. 9, pp. 1465-1477, 2009.

[13] R. J. W. Tijssen, "Global and domestic utilization of industrial relevant science: patent citation analysis of science-technology interactions and knowledge flows," Research Policy, vol. 30, no. 1, pp. 35-54, 2001.

[14] C. V. Trappey, H. Y. Wu, F. Taghaboni-Dutta, and A. J. C. Trappey, "Using patent data for technology forecasting: China RFID patent analysis," Advanced Engineering Informatics, vol. 25, no. 1, pp. 53-64, 2011.

[15] C. Choi and Y. Park, "Monitoring the organic structure of technology based on the patent development paths," Technological Forecasting and Social Change, vol. 76, no. 6, pp. 754-768, 2009.

[16] Y. H. Chen, C. Y. Chen, and S. C. Lee, "Technology forecasting and patent strategy of hydrogen energy and fuel cell technologies," International Journal of Hydrogen Energy, vol. 36, no. 12, pp. 6957-6969, 2011 (Chinese).

[17] A. C. Cheng, C. J. Chen, and C. Y. Chen, "A fuzzy multiple criteria comparison of technology forecasting methods for predicting the new materials development," Technological Forecasting and Social Change, vol. 75, no. 1, pp. 131-141, 2008.

[18] W. B. Ashton and R. K. Sen, "Using patent information in technology business planning-II," Research Technology Management, vol. 32, no. 1, pp. 36-42, 1989.

[19] S. M. Millett and E. J. Honton, A Manager's Guide to Technology Forecasting and Strategy Analysis Methods, Battelle Press, Ohio, USA, 1991.

[20] A. L. Porter, Forecasting and Management of Technology, John Wiley \& Sons, New York, NY, USA, 1991.

[21] S. T. Yeh, "Design application and case study of BIPV in Taiwan," in Proceedings of the 4th Architectural Forum in Taiwan-The Wisdom of Building and Eco-City, National Federation of the Architects Association of the Republic of China, 2007. 
[22] T. Liour, C. W. Chen, C. B. Chen, and C. C. Chen, "White-light LED lighting technology life cycle forecasting and its National and company-wide competitiveness," in Proceedings of the International Conference on Asia Pacific Business Innovation \& Technology Management, pp. 1-14, 2011.

[23] W. T. Chang, Technology development and corporation competence in magneto-resistive random access memory: a study base on USPTO patent [Master's dissertation], Frng Chia University, Taiwan, 2007. 


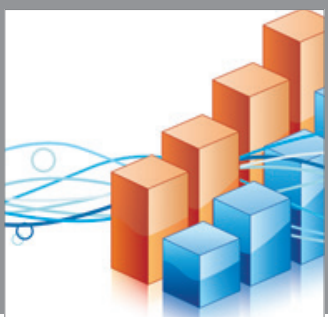

Advances in

Operations Research

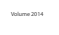

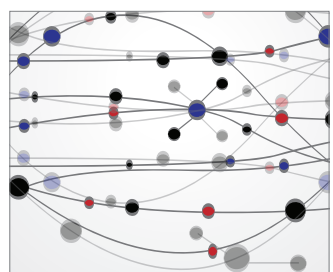

\section{The Scientific} World Journal
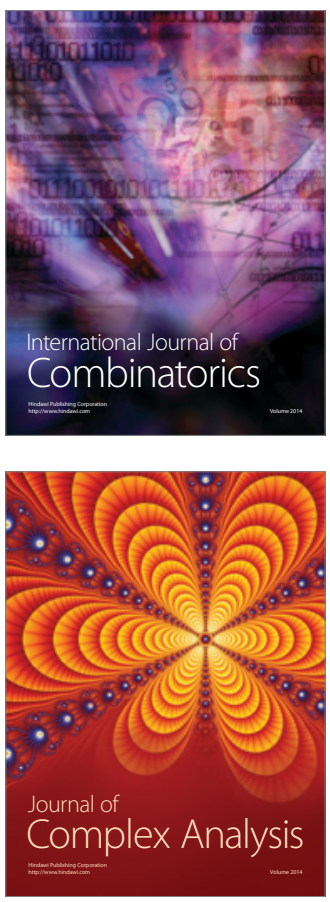

International Journal of

Mathematics and

Mathematical

Sciences
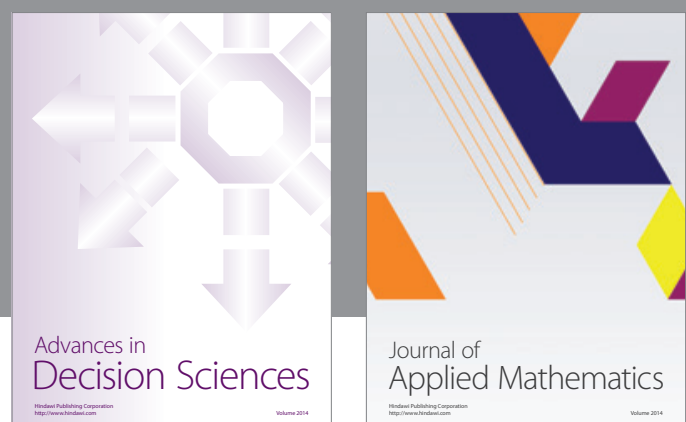

Journal of

Applied Mathematics
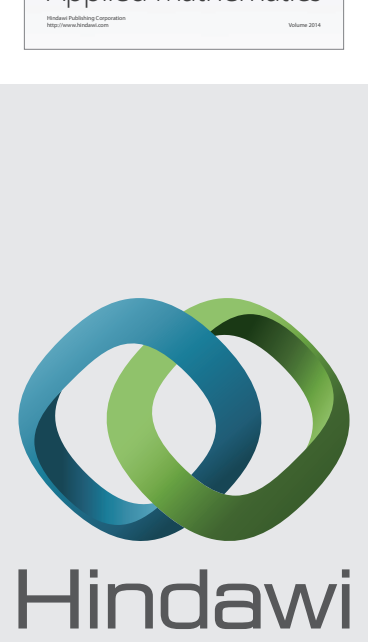

Submit your manuscripts at http://www.hindawi.com
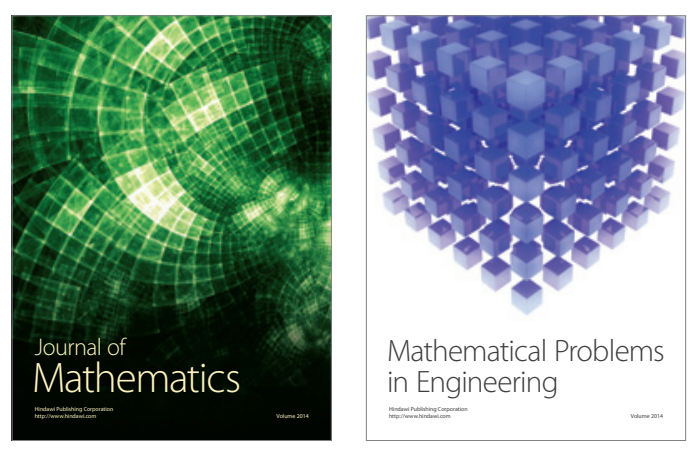

Mathematical Problems in Engineering
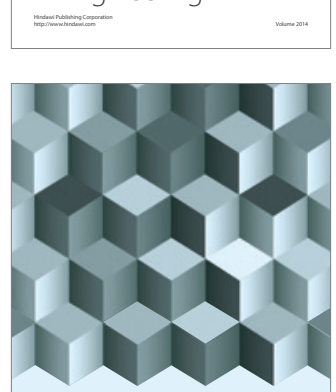

Journal of

Function Spaces
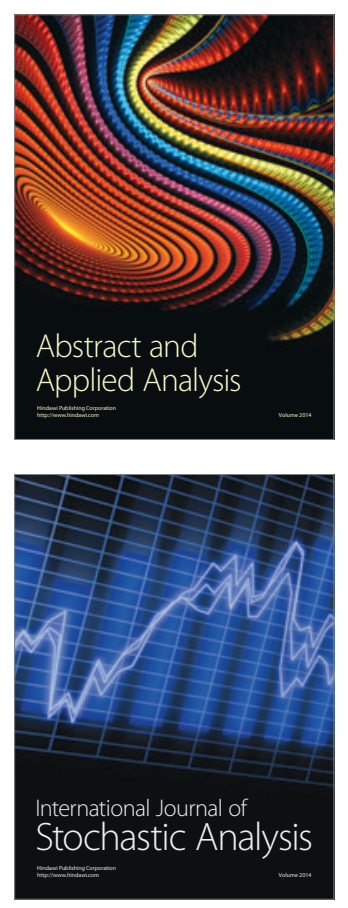

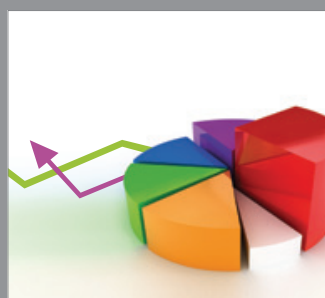

ournal of

Probability and Statistics

Promensencen
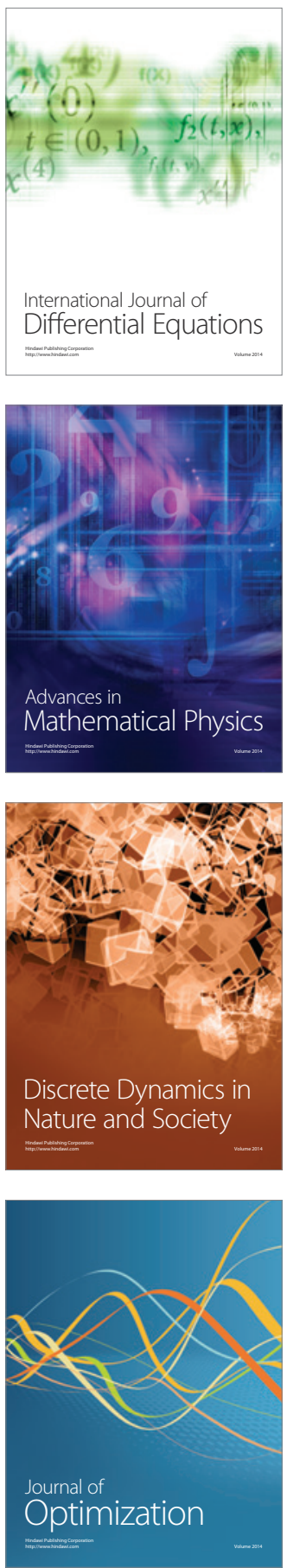